\title{
Implementation intention and planning interventions in Health Psychology: Recommendations from the Synergy Expert Group for research and practice
}

Citation for published version (APA):

Hagger, M. S., Luszczynska, A., de Wit, J., Benyamini, Y., Burkert, S., Chamberland, P-E., Chater, A., Dombrowski, S. U., van Dongen, A., French, D. P., Gauchet, A., Hankonen, N., Karekla, M., Kinney, A. Y., Kwasnicka, D., Lo, S. H., Lopez-Roig, S., Meslot, C., Marques, M. M., ... Gollwitzer, P. M. (2016). Implementation intention and planning interventions in Health Psychology: Recommendations from the Synergy Expert Group for research and practice. Psychology \& Health, 31(7), 814-839. https://doi.org/10.1080/08870446.2016.1146719

Document status and date:

Published: 01/01/2016

DOI:

10.1080/08870446.2016.1146719

Document Version:

Publisher's PDF, also known as Version of record

\section{Document license:}

Taverne

Please check the document version of this publication:

- A submitted manuscript is the version of the article upon submission and before peer-review. There can be important differences between the submitted version and the official published version of record.

People interested in the research are advised to contact the author for the final version of the publication, or visit the DOI to the publisher's website.

- The final author version and the galley proof are versions of the publication after peer review.

- The final published version features the final layout of the paper including the volume, issue and page numbers.

Link to publication

\footnotetext{
General rights rights.

- You may freely distribute the URL identifying the publication in the public portal. please follow below link for the End User Agreement:

www.umlib.nl/taverne-license

Take down policy

If you believe that this document breaches copyright please contact us at:

repository@maastrichtuniversity.nl

providing details and we will investigate your claim.
}

Copyright and moral rights for the publications made accessible in the public portal are retained by the authors and/or other copyright owners and it is a condition of accessing publications that users recognise and abide by the legal requirements associated with these

- Users may download and print one copy of any publication from the public portal for the purpose of private study or research.

- You may not further distribute the material or use it for any profit-making activity or commercial gain

If the publication is distributed under the terms of Article $25 \mathrm{fa}$ of the Dutch Copyright Act, indicated by the "Taverne" license above, 


\section{Implementation intention and planning interventions in Health Psychology: Recommendations from the Synergy Expert Group for research and practice}

Martin S. Hagger, Aleksandra Luszczynska, John de Wit, Yael Benyamini, Silke Burkert, Pier-Eric Chamberland, Angel Chater, Stephan U. Dombrowski, Anne van Dongen, David P. French, Aurelie Gauchet, Nelli Hankonen, Maria Karekla, Anita Y. Kinney, Dominika Kwasnicka, Siu Hing Lo, Sofía LópezRoig, Carine Meslot, Marta Moreira Marques, Efrat Neter, Anne Marie Plass, Sebastian Potthoff, Laura Rennie, Urte Scholz, Gertraud Stadler, Elske Stolte, Gill ten Hoor, Aukje Verhoeven, Monika Wagner, Gabriele Oettingen, Paschal Sheeran \& Peter M. Gollwitzer

To cite this article: Martin S. Hagger, Aleksandra Luszczynska, John de Wit, Yael Benyamini, Silke Burkert, Pier-Eric Chamberland, Angel Chater, Stephan U. Dombrowski, Anne van Dongen, David P. French, Aurelie Gauchet, Nelli Hankonen, Maria Karekla, Anita Y. Kinney, Dominika Kwasnicka, Siu Hing Lo, Sofía López-Roig, Carine Meslot, Marta Moreira Marques, Efrat Neter, Anne Marie Plass, Sebastian Potthoff, Laura Rennie, Urte Scholz, Gertraud Stadler, Elske Stolte, Gill ten Hoor, Aukje Verhoeven, Monika Wagner, Gabriele Oettingen, Paschal Sheeran \& Peter M. Gollwitzer (2016) Implementation intention and planning interventions in Health Psychology: Recommendations from the Synergy Expert Group for research and practice, Psychology \& Health, 31:7, 814-839, DOI: 10.1080/08870446.2016.1146719

To link to this article: $\mathrm{http}: / / d x . d o i . o r g / 10.1080 / 08870446.2016 .1146719$

View supplementary material $\circlearrowright$

Accepted author version posted online: 18 Feb 2016.

Published online: 16 Mar 2016.

Submit your article to this journal

山ll Article views: 350

View related articles ־ 
4 Citing articles: 4 View citing articles ๘

Full Terms \& Conditions of access and use can be found at http://www.tandfonline.com/action/journallnformation?journalCode=gpsh20 


\section{Implementation intention and planning interventions in Health Psychology: Recommendations from the Synergy Expert Group for research and practice}

Martin S. Hagger ${ }^{\mathrm{a}, \mathrm{b}, \mathrm{c}, \mathrm{d} *}$ (D), Aleksandra Luszczynska ${ }^{\mathrm{e}, \mathrm{f}_{*}}, \mathrm{John}_{\mathrm{de}} \mathrm{Wit}^{\mathrm{g}}{ }^{\mathbb{D}}$, Yael Benyamini $^{\mathrm{h}}$, Silke Burkert ${ }^{\mathrm{i}}$, Pier-Eric Chamberland ${ }^{\mathrm{j}}$, Angel Chater ${ }^{\mathrm{k}}$, Stephan U. Dombrowski $^{1}$, Anne van Dongen ${ }^{\mathrm{m}}$, David P. French ${ }^{\mathrm{n}}$, Aurelie Gauchet ${ }^{\mathrm{o}}$, Nelli Hankonen $^{\mathrm{p}}$, Maria Karekla ${ }^{\mathrm{q}}$, Anita Y. Kinney ${ }^{\mathrm{r}}$, Dominika Kwasnicka ${ }^{\mathrm{a}}$, Siu Hing Lo ${ }^{\mathrm{s}}$, Sofía López-Roig ${ }^{\mathrm{t}}$, Carine Meslot ${ }^{\mathrm{o}}$, Marta Moreira Marques ${ }^{\mathrm{u}}$, Efrat Neter ${ }^{\mathrm{v}}$, Anne Marie Plass $^{\mathrm{w}}$, Sebastian Potthoff ${ }^{\mathrm{x}}$, Laura Rennie ${ }^{\mathrm{y}}$, Urte Scholz ${ }^{\mathrm{z}}$, Gertraud Stadler ${ }^{\mathrm{aa}}$, Elske Stolte $^{\mathrm{bb}}$, Gill ten Hoor ${ }^{\mathrm{cc}}$, Aukje Verhoeven ${ }^{\mathrm{dd}, \mathrm{ee}}$, Monika Wagner ${ }^{\mathrm{ff}}$, Gabriele Oettingen $^{\text {gg,hh }}{ }^{\text {, Paschal Sheeran }}{ }^{\mathrm{ii}}$ and Peter M. Gollwitzer ${ }^{\text {gg,jj }}$

${ }^{a}$ Health Psychology and Behavioural Medicine, School of Psychology and Speech Pathology, Faculty of Health Sciences, Curtin University, Perth, Australia; ${ }^{b}$ School of Applied Psychology and Menzies Health Institute Queensland, Griffith University, Brisbane, Australia; ' $S$ chool of Human, Health and Social Sciences, Central Queensland University, Rockhampton, Australia; ${ }^{d}$ Faculty of Sport and Health Sciences, Department of Sport Sciences, University of Jyväskylä, Jyväskylä, Finland; ${ }^{e}$ University of Social Sciences and Humanities, Wroclaw, Poland; ${ }^{f}$ Trauma, Health, \& Hazards Center, University of Colorado at Colorado Springs, Colorado Springs, USA, ${ }^{g}$ Centre for Social Research in Health, Faculty of Arts and Social Sciences, University of New South Wales, Sydney, Australia; ${ }^{h}$ Bob Shapell School of Social Work, Tel Aviv University, Tel Aviv, Israel; ${ }^{i}$ Institut für Medizinische Psychologie, Charité Universitätsmedizin Berlin, Berlin, Germany; ${ }^{j}$ Département de psychologie, Université du Québec à Trois-Rivières, Trois-Rivières, Canada $;{ }^{k}$ School of Pharmacy, Centre for Behavioural Medicine, Department of Practice and

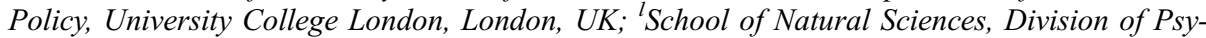
chology, University of Stirling, Stirling, UK; ${ }^{m}$ Sanquin Blood Supply Foundation, Amsterdam, The Netherlands; ${ }^{n}$ School of Psychological Science, University of Manchester, Manchester, UK; ${ }^{\circ}$ Laboratoire Interuniversitaire de Psychologie Personnalité, Cognition, et Changement Social, Université Grenoble Alpes, Grenoble, France; ${ }^{p}$ Department of Social Research, University of Helsinki, Helsinki, Finland; ${ }^{q}$ Department of Psychology, University of Cyprus, Nicosia, Cyprus; ${ }^{r}$ Department of Internal Medicine, University of New Mexico, Albuquerque, USA; ${ }^{s}$ Research Department of Epidemiology and Public Health, Health Behaviour Research Centre, University College London, London, UK; ${ }^{t}$ Departamento de Psicología de la Salud, Facultad de Medicina, Universidad Miguel Hernández de Elche, Elche, Spain; ${ }^{u}$ CIPER, Faculty of Human Kinetics, University of Lisbon, Lisbon, Portugal; " Ruppin Academic Centre, Emek Hefer, Netanya, Israel;

${ }^{w}$ Netherlands Institute for Health Services Research (NIVEL), Utrecht, The Netherlands; ${ }^{x}$ Institute of Health \& Society, Newcastle University, Newcastle, UK; ${ }^{y} B$-Research/Université Paris-Ouest Nanterre La Défense, Paris, France; ${ }^{z}$ Department of Psychology, Applied Social Psychology, University of Zurich, Zurich, Switzerland; ${ }^{a}$ Department of Psychology, Columbia University,

New York, USA; ${ }^{b b}$ Department of Sociology, Faculty of Social Sciences, VU Amsterdam, Amsterdam, The Netherlands; ${ }^{c c}$ Psychology and Neuroscience, Work and Social Psychology, Applied Social Psychology, Maastricht University, Maastricht, The Netherlands; ${ }^{d d}$ Clinical \& Health Psychology, Faculty of Social Sciences, Utrecht University, Utrecht, The Netherlands; ${ }^{e e}$ Department of Clinical Psychology, University of Amsterdam, Amsterdam, The Netherlands;

${ }^{f f}$ Department of Medical Psychology, Medizinischen Universität Innsbruck, Innsbruck, Austria;

${ }^{g g}$ Department of Psychology, New York University, New York, USA; ${ }^{h}$ Department of Psychology 
and Human Movement, University of Hamburg, Hamburg, Germany; ${ }^{i i}$ Department of Psychology, University of North Carolina, Chapel Hill, USA; ${ }^{j j}$ Department of Psychology, University of Konstanz, Konstanz, Germany

(Received 17 March 2015; accepted 21 January 2016)

\begin{abstract}
The current article details a position statement and recommendations for future research and practice on planning and implementation intentions in health contexts endorsed by the Synergy Expert Group. The group comprised worldleading researchers in health and social psychology and behavioural medicine who convened to discuss priority issues in planning interventions in health contexts and develop a set of recommendations for future research and practice. The expert group adopted a nominal groups approach and voting system to elicit and structure priority issues in planning interventions and implementation intentions research. Forty-two priority issues identified in initial discussions were further condensed to 18 key issues, including definitions of planning and implementation intentions and 17 priority research areas. Each issue was subjected to voting for consensus among group members and formed the basis of the position statement and recommendations. Specifically, the expert group endorsed statements and recommendations in the following areas: generic definition of planning and specific definition of implementation intentions, recommendations for better testing of mechanisms, guidance on testing the effects of moderators of planning interventions, recommendations on the social aspects of planning interventions, identification of the preconditions that moderate effectiveness of planning interventions and recommendations for research on how people use plans.
\end{abstract}

Keywords: implementation intentions; planning; volition; if-then plans; goal striving; cues-to-action

There has been a proliferation of theory and research using planning-based interventions to change health-related behaviour (Gollwitzer, 2014; Hagger \& Luszczynska, 2014). Much of this research has been driven by the evidence of a disparity between individuals' reports of positive intentions committing them to a course of action and their actual behavioural enactment in health contexts, colloquially referred to as the intentionbehaviour 'gap' (Orbell \& Sheeran, 1998; Rhodes \& de Bruijn, 2013a, 2013b; Sheeran, 2002; Sniehotta, Scholz, \& Schwarzer, 2005). Weak intentions and motivation towards participation in health behaviour remain a problem for many individuals (Abraham, Sheeran, \& Johnston, 1998; Armitage \& Conner, 2000; Schwarzer, 2008b; Webb, Sniehotta, \& Michie, 2010; Weinstein, 2007). Efforts to promote motivation and strengthen intentions to engage in health behaviour, the focus of many theory-based health-behaviour interventions, are therefore paramount (Orbell \& Sheeran, 1998). However, there is recognition that a substantial number of individuals are motivated to

*Corresponding authors. Email: martin.hagger@curtin.edu.au (M.S. Hagger); aluszczy@uccs.edu (A. Luszczynska)

This research reported in this article was conducted as part of the European Health Psychology Society's (EHPS) Synergy Expert Meeting held in 2014 in Innsbruck, Austria facilitated by Martin S. Hagger, Aleksandra Luszczynska, and John de Wit. The EHPS Synergy expert meetings are organised annually to facilitate collaborative discussion between health psychologists conducting research in core fields within health psychology. 
engage in health behaviour and form goal intentions to do so, but fail to carry out those intentions (Gollwitzer, Sheeran, Michalski, \& Seifert, 2009; Rhodes \& Dickau, 2012). These individuals are often referred to as 'inclined abstainers' (Orbell \& Sheeran, 1998) or 'unsuccessful intenders' (Rhodes \& de Bruijn, 2013a). Reasons for individuals' failure to act on their goal intentions may be because they are insufficiently specified by the individual, individuals forget to carry them out, or other more attractive opportunities or alternatives arise that distract the individual from initiating the action (Gollwitzer, 1993). Interventions that focus solely on motivation and intentions may, therefore, have a limited impact in changing the health behaviour of these individuals because they have already formed goal intentions to change (Orbell \& Sheeran, 2000; Webb \& Sheeran, 2006). This has led to increased focus on the processes by which intentions are enacted.

A number of social psychological theories and models have proposed that the enactment of intentions occurs at a separate 'stage' or 'phase' to intention formation and it is processes in this stage that determine the extent to which intentions are converted into action (Hagger \& Chatzisarantis, 2014; Heckhausen \& Gollwitzer, 1987; Rhodes \& de Bruijn, 2013a; Rhodes, Fiala, \& Nasuti, 2012; Schwarzer, 2008a). Such 'action-control' frameworks suggest that volitional processes operating in a post-intentional manner determine the enactment of intentions. Action-control frameworks were pioneered in the model of action phases (Gollwitzer, 1990; Heckhausen \& Gollwitzer, 1987) and have later been incorporated in other frameworks including the health action process approach (HAPA; Schwarzer, 2008a), the I-Change model (de Vries, Mesters, van de Steeg, \& Honing, 2005), and others (e.g. Fuchs, Seelig, Göhner, Burton, \& Brown, 2012; Hagger \& Chatzisarantis, 2014). Separate intentional and volitional phases are common to these approaches and describe the processes by which individuals perform their intended behaviours to attain their goals. According to the model of action phases, individuals enact their intentions in the volitional phase by augmenting goal intentions with volitional components such as plans.

In its prototypical form, planning in the context of the action-phase framework is conceptualised as forming implementation intentions, that is, specifying a critical cue $x$ and pairing it with a goal-directed response $y$ (Gollwitzer, 1999). Formally defined, implementation intentions require individuals, who have formed an intention to attain a particular outcome or goal $z$, to specify a cue or condition $x$, which will mark a goal-directed behavioural response $y$ (Brandstätter, Lengfelder, \& Gollwitzer, 2001; Gollwitzer, 1999; Gollwitzer \& Brandstätter, 1997). Implementation intentions are typically specified in an ifthen format (e.g. 'If condition $x$ is encountered, then I will perform goal-directed response $y$ !'). Implementation intentions are effective in resolving some of the problems individuals face when attempting to initiate and persist with their goal intentions. Problems initiating action and difficulties in shielding goal striving from unwanted distractions or alternatives can undermine goal attainment. Making plans to deal with these contingencies in advance of behavioural enactment is an effective strategy to assist individuals in the realisation of their goal intentions. Research has also demonstrated that the mechanism by which implementation intentions may exert their effects on behavioural enactment is through improving perceptual readiness for the specified cues (Gollwitzer, 2014; Orbell, Hodgkins, \& Sheeran, 1997; Webb \& Sheeran, 2004; Wiedemann, Lippke, \& Schwarzer, 2012) and increasing the automaticity (i.e. fast, efficient, and without conscious intent) by which the intended behaviour is enacted (Sheeran, Webb, \& Gollwitzer, 2005; Webb \& Sheeran, 2008; Webb, Sheeran, \& Luszczynska, 2009). 
Although implementation intentions are a prototypical form of planning, other similar but distinct approaches to planning exist and have been successfully applied to promoting behaviour in health contexts. Prominent among these alternative approaches are action planning and coping planning (Schwarzer, 2008a). Action planning shares similar defining characteristics to implementation intentions, although their underpinning theoretical paradigms are somewhat different. Coping plans reflects plans to maintain a goal-directed behaviour in the face of contingencies that arise during behavioural enactment that may derail the action. In fact, both action planning and coping planning have some overlap with implementation intentions. As Gollwitzer and Sheeran (Gollwitzer, 1993, 1999; Gollwitzer \& Sheeran, 2006) pointed out, implementation intentions can be used to promote action initiation as well as to protect ongoing goal pursuit from intrusions (Gollwitzer, 1999). (Schwarzer 2008a; Schwarzer, Lippke, \& Ziegelmann, 2008) highlights this fact by referring to implementation intentions that promote action initiation as action plans and to implementation intentions that stabilise an ongoing goal pursuit as coping plans. Action plans and coping plans are often used conjointly to enable individuals to get started and to manage foreseen contingencies that arise during behavioural enactment (Kwasnicka, Presseau, White, \& Sniehotta, 2013; Sniehotta, Scholz, \& Schwarzer, 2006; Sniehotta, Schwarzer, Scholz, \& Schüz, 2005).

The relative simplicity and effectiveness of planning and implementation intention interventions has led to a burgeoning number of tests of the effect and it is one of the most used and cited techniques in health-behaviour interventions (Hagger \& Luszczynska, 2014). The popularity of planning and implementation intentions and the consistency in its effects notwithstanding, numerous questions remain. Meta-analyses have demonstrated that implementation intentions have medium-sized effects on behavioural outcomes in health contexts, but identified some heterogeneity in the effects (Adriaanse, Vinkers, De Ridder, Hox, \& De Wit, 2011; Bélanger-Gravel, Godin, \& Amireault, 2013; Carraro \& Gaudreau, 2013; Gollwitzer \& Sheeran, 2006) and there are a number of tests that have shown no effects of implementation intentions on behavioural enactment (Adriaanse, de Ridder, \& de Wit, 2009; De Vet, Oenema, Sheeran, \& Brug, 2009; Jackson et al., 2005; Leventhal, Diefenbach, \& Leventhal, 1992; Lo et al., 2013; Michie, Dormandy, \& Marteau, 2004). Attention has therefore focused on the factors that might magnify or diminish the effects of planning and implementation intention interventions in health contexts. In addition, researchers have also sought to further test the boundary conditions for the effectiveness of planning and implementation intentions and identify a core set of candidate mediators of the effects (Scholz, Schüz, Ziegelmann, Lippke, \& Schwarzer, 2008). These emerging questions have been the catalyst of much research in the field and there have been recent attempts to draw existing research and theoretical approaches together with the aim of arriving at a set of recommendations for future research and practice.

\section{The aims of the Synergy Expert Group on planning and implementation intentions}

In August 2014, the European Health Psychology Society Synergy Meeting assembled a group of world-leading experts in the field of planning and implementation intentions with the goal of identifying and discussing the key issues with respect to planning interventions in health-related behavioural contexts, and develop a set of 'best practice' guidelines for research and practice. The focus was to systematically pool ideas and share current knowledge on planning research theory and practice guided by, but not limited to, five general 
areas identified a priori by the meeting convenors based on a recent narrative review (Hagger \& Luszczynska, 2014) to assist initiating and guiding discussion ${ }^{1}$ :

\section{Operationalisation and definitions}

How should planning and implementation intentions be defined? What should implementation intention and other planning interventions 'look like'? What are the essential, basic components?

\section{Mechanisms}

What are the 'knowns' and 'unknowns' of how planning and implementation intentions work? What are the candidate factors that mediate the effect of implementation intentions on health behaviour?

\section{Design issues}

How should planning and implementation intentions interventions be tested in health contexts? What would be the fundamental components of planning and implementation intention intervention studies? What procedures should be included in studies to ensure adequate evaluation of planning and implementation intention interventions?

\section{Key constructs and measures}

What key measures are needed to evaluate the effectiveness of planning and implementation intention interventions?

\section{Moderators}

Under what conditions are planning and implementation intentions most effective? What factors may magnify or diminish the effect of planning and implementation intentions on health behaviour?

Importantly, the focus of the expert group was to develop a set of recommendations in the above areas based on consensus among the expert and current knowledge that will assist researchers and interventionists in developing and evaluating effective planning and implementation intention interventions in health contexts. A primary goal of the recommendations was to identify gaps in knowledge and inform future research priorities that will move theory on planning and implementation intentions intervention in health contexts forward. The current article summarises the proceedings of the expert meeting and catalogues the recommendations that emerged from the discussions.

Although the scope of the expert group meeting was not limited to particular types of techniques or interventions and there was no a priori stipulation of a focus on any particular conceptual or theoretical paradigm, the emerging consensus among group members was largely confined to implementation intentions conceptualised as 'if-then' type plans. The scope of the current recommendations and guidelines is therefore limited to implementation intentions or if-then plans and, as a consequence, adopts terminology and operational definitions specific to this type of planning. 


\section{Method}

\section{Participants}

Participants $(N=32)$ were the members of the Synergy Expert Group on planning and implementation intentions. The group comprised active researchers with experience in developing and conducting original research using implementation intentions or planning interventions in health contexts and had demonstrable evidence of scholarly activity in the field. Members of the group were selected from applications to participate in the expert group meeting. Applicants responded to an advertisement outlining the topic and agenda of the meeting and were informed that they had to demonstrate previous experience in research with implementation intention or planning interventions and that the meeting was aimed at advanced-level researchers. Examples of evidence of active research and involvement in implementation intention or planning interventions included: (1) involvement in previous peer-reviewed research on implementation intention or planning interventions; (2) enrolment in a high-degree by research at an accredited higher-education institution with a proposal that had been reviewed and approved by the institution and with a supervisor or supervisory team that had demonstrable evidence of a track record in implementation intentions or planning research; or (3) demonstrable use of implementation intention or planning techniques in a large-scale intervention or trial in a health context. Applications were screened and approved or rejected by the EHPS Synergy Committee and lead facilitators of the Expert Meeting and applicants were informed of the decision. Meeting activities were developed a priori and proceedings were facilitated by the lead authors (MSH, AL, and JdW). The facilitators circulated materials including an agenda of potential topics for discussion and salient review articles on implementation intention and planning interventions to the group members in advance of the meeting. Members were informed that they should self-identify their areas of expertise within the broad area of planning interventions and outline key issues and priorities for research and practice. Participants were also informed in advance that the goal of the expert meeting was to develop a position statement that would be submitted for publication which incorporated the views of the participants. Participants were informed that their attendance at the meeting constituted their agreement to participate in the meeting activities and the subsequent preparation of the position statement. They were also informed that they would be consulted in the development of the position statement and their written approval would be solicited prior to any submission in which they were listed as co-author. They were also informed of their right to withdraw from the meeting and any subsequent position statement and submission. The study was submitted for consideration and received a waiver from Internal Review Board at the second author's institution.

\section{Procedure}

A number of approaches have been developed to elicit discussion and establish consensus among members of expert panels. The RAND/UCLA appropriateness method (RAM) aims to identify recommendations for best practice in performing diagnostic and treatment procedures applied in clinical practice (Fitch et al., 2001). The RAM is recommended when there is good empirical evidence in support of the issue (e.g. multiple randomised controlled trials and systematic reviews) and when the outcomes are clearly 
defined (e.g. mortality rates; Fitch et al., 2001). This evidence is used by facilitators to develop a highly structured list of indicators and definitions; the list is then delivered to the panel which conducts a discussion that is tightly focused on the basic measure of appropriateness (i.e. ratio of benefit relative to harm) of the treatment methods (Fitch et al., 2001). Another approach, the 'consensus development conference', aims to address a specific, narrow and predefined question on a particular issue or topic (Kanouse et al., 1989). Practitioners, researchers and consumers or patients are charged with developing consensus among experts in a process comprising literature reviews, state of knowledge summaries, presentations by experts and advocates and discussions among audience members. Finally, the 'nominal group approach' is aimed at defining areas, terminology and concepts, and addressing key questions, on a particular issue or topic using a process of consensus among groups members (Delbecq \& van de Ven, 1971; Fink, Kosecoff, Chassin, \& Brook, 1984, 1991). In contrast to RAM, the nominal group approach starts with panel members writing down their initial ideas on the issue or topic followed by a session in which they briefly describe their initial ideas to the panel. The stimulus for discussion is, therefore, ideas generated by each group member individually prior to group discussion.

The RAM may be most appropriate to arrive at consensus among members of an expert group when there is an established body of empirical evidence to be considered and the focus is on selecting the most appropriate procedures for specific diagnoses and treatment in clinical practice. Consensus development conferences are feasible when the best practice guidelines are implementation-ready and when the purpose is narrowed down to a small set of specific questions about practice recommendations, confirmed by researchers, practitioners and consumers. In contrast, the nominal group approach may be the more feasible when the empirical evidence does not permit the preselection of definitions, methods, and salient outcomes of a particular topic, and when the purpose is broader than to agree on procedures for best practice. Due to the breadth of the issue of planning interventions, the nominal group approach was considered the most appropriate method to guide discussion and arrive at consensus among members of the expert group.

The current position statement on best practice and priority areas for future research on implementation intentions was developed over the course of a two-day meeting during which participants engaged in activities designed to stimulate discussion, promote debate, and identify points of common agreement. Upon attending the meeting, participants were further informed of the purpose and methods of the meeting and provided with a brief overview introducing the topic, a review of the current literature, and the list of five general areas identified a priori based on a previous review of the planning literature (Hagger \& Luszczynska, 2014). Importantly, they were told that the purpose of providing the general areas was to guide discussion, rather than confine it, and that they were free to discuss any other ideas that may not fall under the specific headings. Participants were then given an opportunity to introduce themselves, outline their area of expertise within the field of planning interventions, and identify their interest in the meeting.

The meeting adopted the nominal group method to facilitate discussion and promote consensus among expert group members on key issues relating to planning and implementation intentions interventions in the specified priority areas (Delbecq \& van de Ven, 1971; Fink et al., 1984, 1991; Van de Ven \& Delbecq, 1972). The nominal group 
approach is defined as 'a structured meeting that attempts to provide an orderly procedure for obtaining qualitative information from a target group who is most closely associated with a problem area' (Fink et al., 1984, p. 980). The process of developing consensus among group members using this approach followed the three loosely structured steps under the guidance of the facilitators:

Step 1. Participants were initially asked to engage in some 'individual work' and write down their own personal list of topics in need of discussion and questions regarding the key issues under one or more of the guideline areas. After completing the list, each member was asked to provide a summary presentation of their key issues. The issues were recorded on a chart and the process was repeated until participants' lists were exhausted. The list was refined and redundancies removed and then consolidated under key areas (see Fink et al., 1984).

Step 2. Next, the expert group conducted a structured discussion of all generated issues (Fink et al., 1984). The purpose of this step was to clarify, refine and evaluate the worth of the issues raised. Participants formed six small groups in areas of common interest derived from the chart developed in Step 1 and then engaged in a series of discussions. The small groups analysed the issues classified into six broad categories that closely followed the general areas specified a priori to guide discussions: (1) operationalisations and definitions; (2) mechanisms; (3) format-related moderators; (4) social aspects of planning and implementation intentions; (5) preconditions of planning and implementation intentions; and (6) the ways people use plans. The purpose of the discussions was to conduct a thorough groupbased analysis and clarification of the key issues with the addition of new information that emerged as a result of the discussions. Discussions were systematic and thorough, addressing items one at a time, rather than the list in its entirety (Van de Ven \& Delbecq, 1972). Further debate was encouraged by asking participants to systematically visit other small groups for further discussion and cross-fertilisation of ideas. We did this by assigning numbers to all experts (the same set of numbers was used for each small group) and asking experts with the same number to circulate until each participant had visited all groups. This stage was concluded with the members of the original small groups convening together and refining their list of issues. The issues identified by the small groups were recorded in a spreadsheet (Van de Ven \& Delbecq, 1972).

Next, a plenary discussion was conducted. Representatives from each small group referred the key issues identified in their discussions to the larger group. The facilitators encouraged further discussion on each issue to further evaluate its worth. The plenary discussion provided all participants with opportunity to raise questions and debate issues in an open forum. These discussions were not only designed to permit members of the small groups to present their ideas and allow others to discuss to debate any emergent issues, but to highlight any potential 'narrow' approaches or 'groupthink' scenarios that might have arisen during the course of the small group discussions. The result of plenary discussion was further refinement and focusing of the list of the key issues. 
Step 3. When the discussion was completed, each participant took some time to privately reflect on, and rate, the value of the issues (Van de Ven \& Delbecq, 1972). The views of the small group members were subsequently discussed and summarised in an open forum.

\section{Consensus voting}

There are many possible criteria that define when consensus among group members is reached. In line with the guidelines for consensus methods (Fink et al., 1984, 1991), the level and the type of consensus was defined at the beginning of the expert group meeting. In particular, to gauge and evaluate consensus among group members of the shortlisted issues we employed the voting procedure guidelines developed by Fink et al. (1991). Participants were asked to cast their vote as to whether they endorsed each presented issue and its wording, disagreed, or abstained. The expert group participants agreed that any issue that received at least $66 \%$ of participants' votes would be adopted while any topic opposed by at least $25 \%$ of participants would be flagged as a 'controversial' issue. The results of the voting were counted by two expert group members, recorded and displayed immediately. The votes of expert group members who were absent during the voting were not included into the vote count. Twenty-eight members were present during voting and cast their votes. The voting was followed by a final round of discussions among all Expert Group members conducted in an open forum and summarised by the facilitators.

\section{Results \\ Participants}

Participants in the Synergy Expert Group completed a brief demographic and expertise survey and results are summarised in Appendix A (as online supplemental materials). Participants reported having experience in multiple areas of implementation intention and planning research. Group members had an average of 8.48 years $(\mathrm{SD}=6.42$, range 1-30) experience in the field of implementation intention and planning research. Together participants had authored or coauthored over 220 peer-reviewed research articles in the field of implementation intentions or planning research, with research appearing in leading journals in health psychology and behavioural medicine and applied fields. The group included researchers at the forefront of the conceptual and theoretical development of implementation intentions and planning interventions in general and in the context of health behaviour. The group also included doctoral students and early career-researchers, who were considered by the Synergy Committee to satisfy the criterion for the participation of engaging in current research in the field of implementation intentions and planning interventions as demonstrated by submitted peer-reviewed work or enrolment in a high degree approved by a higher-education institution or an appropriate supervisor or supervisory team working in the field. The group also included researchers in clinical contexts with experience in developing and evaluating health behaviour interventions adopting planning techniques. Participants' expertise also included implementation of planning interventions in real-life settings, translational 
research and collaboration with respective stakeholders. Although the meeting was hosted by the EHPS group, a European-based organisation, the expert group was international in perspective with researchers' primary-affiliated institution or organisation located in Australia $(n=2)$, Austria $(n=1)$, Canada $(n=1)$, Cyprus $(n=1)$, Finland $(n=1)$, France $(n=2)$, Germany $(n=1)$, Israel $(n=2)$, the Netherlands $(n=6)$, Poland $(n=1)$, Portugal $(n=1)$, Spain $(n=1)$, Switzerland $(n=1)$, United Kingdom $(n=6)$, and the United States of America $(n=5)$. The primary discipline with which participants identified included health psychology and behavioural medicine $(n=19)$, clinical psychology $(n=1)$, social psychology $(n=11)$ and community genetics $(n=1)$. Participants were also working in, or had previous experience with, the disciplines of developmental psychology, medical psychology, implementation science, population science, and nursing. Group members reported experience of applying implementation intention or planning interventions to a broad spectrum of health-related behaviours, including physical activity, healthy eating and dietary behaviours, alcohol reduction, smoking cessation, medication adherence, cancer screening, sexual health behaviours, dental flossing, vaccination behaviours, oral hydration behaviours, emotion control and anxiety management and blood donation. Participants also indicated that their research had been conducted in a diverse range of demographic groups, including patients with chronic illnesses and conditions (e.g. asthma, cancers, cardiovascular disease, chronic fatigue, chronic pain, diabetes, epilepsy, obesity), patients with anxiety and emotional disorders, organ transplant patients, people with eating disorders, people with alcohol dependency, people in high-risk groups (e.g. people at risk of sexually transmitted infections), healthcare professionals, children with ADHD, pregnant women, older adults, students, blood donors and school teachers.

\section{Initial priority areas}

Step 1 of the nominal group procedures led to the development of an initial list of issues representing priority areas that were subjected to discussion and debate in small groups (Step 2). The initial list is presented in Appendix B (as online supplemental materials) grouped under the five headings identified a priori: operationalisation and definitions, mechanisms, design issues, key constructs and measures and moderators. The list presented in Appendix B indicates that many of the areas of priority identified by participants focused on design, methodological issues, the practice of planning interventions and the effects of moderators likely to influence planning intervention effectiveness.

This initial priority list, obtained in Step 1, was subsequently truncated and refined in Step 2. The final shortlist included 18 issues. These 18 issues were then further discussed and recommendations were subjected to the voting procedure as an assessment of overall consensus among members of the Expert Group (Fink et al., 1991). The votes provided final consensus of the key issues identified and the position of the Expert Group.

\section{Final priority areas}

The expert group proposed the following 18 priority issues, including planning definition and priority issues for research (Appendix C, as online supplemental materials). The 
issues were organised into six priority areas. ${ }^{2}$ All issues received more than two-thirds of the votes and, therefore, met the agreed criterion for inclusion in the position statement.

\section{Operationalisation and definitions}

- Planning is one means to attain goals. Implementation intentions are a form of planning that specify a critical condition linked to goal-directed response (votes for 19 [68\%], votes against 5, abstentions 4).

The definition issue was extensively debated and occupied a considerable proportion of time of the plenary discussions and voting procedure. The Group discussed making distinctions between different types of plans and the underpinning theoretical paradigms. In particular, the debate centred around the distinction between planning as a generic term and specific forms of plans from different, yet overlapping, theoretical paradigms, such as implementation intentions within the model of action phases (Brandstätter, Heimbeck, Malzacher, \& Frese, 2003; Gollwitzer, 1990; Heckhausen \& Gollwitzer, 1987) and action planning from the HAPA (e.g. Schwarzer \& Luszczynska, 2008). The final definition received endorsement from a large majority of the participants present during the voting and resulted in a proposal for a generic definition of planning and a definition of implementation intentions as a specific form.

\section{Mechanisms}

It is recommended that researchers ...

- ... explore different ways of eliciting self-regulatory problems as a starting point in order to better inform planning formation (votes for 28 [100\%], 0 against, 0 abstentions).

- ... examine how best to inform/reinforce cue-response strength to improve planning intervention effectiveness (votes for 28 [100\%], 0 against, 0 abstentions).

- ... examine how best to specify the if/then components of implementation intentions/planning interventions (votes for 28 [100\%], 0 against, 0 abstentions).

One of the key issues that arose in discussions was enabling individuals engaged in planning interventions to specify the self-regulatory problem to be solved and the critical obstacle that stands in the way of solving the problem (Oettingen, 2012, 2014; Oettingen, Pak, \& Schnetter, 2001) before developing plans, and this formed the first recommendation of this section. Research examining means to elicit individuals' self-regulatory problems prior to planning was considered important to enable individuals to specify plans that directly address the self-regulatory problem and the required behavioural response, i.e., the ' $y$ ' in the generalised formulation of implementation intentions: 'If condition $x$ is encountered, then I will perform goal-directed response $y$ !' It was also considered important to investigate how individuals might identify self-regulatory problems and means to promote a better capacity to do so (Hagger, 2010). This received unequivocal support from expert group participants. 
Another issue considered essential by the expert group was further investigation on how best to ensure that the link between the critical condition and cue (the ' $x$ ' in the generalised form) and the behavioural response (the ' $y$ ') (e.g. Verhoeven, Adriaanse, de Vet, Fennis, \& de Ridder, 2014) is reinforced and how the cue can be made more potent in evoking a behavioural response. Such means may include strategies relating to the mode in which individuals specify the plans or implementation intention (e.g. repetitions in the writing of plans, requiring participants to 'press harder' on a pen when writing out their plan). Similarly, the effectiveness of the specification of the if-then components of implementation intentions was also universally endorsed as a priority. Further investigations may examine moderation of the effect of plans on behavioural enactment by the way in which plans are specified. The way in which the plan is specified may include the number of times the plan is recited or rehearsed, the specificity or construal level of the 'if' component compared to the 'then' given the importance of stating a specific behavioural response (e.g. examining the effect of specifying the 'if' component in more general terms such as an array of similar situations compared to specifying it as more specific to the unique behaviour), and increasing the congruency between the plan and the self.

\section{Moderators and contexts}

Future research should consider ...

- ... the effect of new and established intrapersonal moderating factors on the effectiveness of implementation intention/planning interventions (votes for 22 [79\%], votes against 0 , abstentions 6).

- ... the effect of language, mode of delivery (e.g. self-generated vs. prescribed) on the effectiveness of implementation intention/planning interventions (votes for 22 [79\%], votes against 0 , abstentions 6).

- ... the type of response as a moderator of the effectiveness of implementation intention/planning interventions (votes for 22 [79\%], votes against 0 , abstentions $6)$.

- ... the design of more engaging planning interventions for specific groups (votes for 25 [89\%], votes against 2, abstentions 1).

The discussions resulted in strong support for future investigations focusing on identifying possible intrapersonal factors (e.g. personality, individual differences; Churchill \& Jessop, 2010; Luszczynska, Schwarzer, Lippke, \& Mazurkiewicz, 2011; Prestwich \& Kellar, 2014; Webb, Christian, \& Armitage, 2007), format and delivery modes (Armitage, 2009; Chapman, Armitage, \& Norman, 2009), and type of behavioural response such as engaging in a health behaviour (healthy eating, physical activity) or disengaging from an unhealthy behaviour (e.g. reducing alcohol content, avoiding unhealthy foods; Adriaanse et al., 2011; Chatzisarantis \& Hagger, 2010; Hagger et al., 2012; Luszczynska, Sobczyk, \& Abraham, 2007) that moderate the effectiveness of planning interventions. These types of moderating variables featured prominently on the long list of initial priority areas. This is consistent with observations in the literature that, given the heterogeneity in the effect sizes of meta-analytic reviews of planning and implementation intention effects, identifying the conditions under which implementations 
are optimally effective and engaging for target groups is a priority (Bélanger-Gravel et al., 2013; Hagger \& Luszczynska, 2014). Translating theory-based behaviour change methods or techniques into practical applications demands a sufficient understanding of the theory behind the method and especially the theoretical parameters or conditions that limit the effectiveness of the theoretical process (Bartholomew, Parcel, Kok, Gottlieb, \& Fernández, 2011; de Bruin, Crutzen, \& Peters, 2015; Peters, de Bruin, \& Crutzen, 2015).

\section{Social aspects of planning}

- It is feasible to use collaborative $\mathrm{e}^{3}$ and dyadic $^{4}$ planning in planning/implementation intention interventions (votes for 28 [100\%], 0 against, 0 abstentions).

- Future research should examine for whom and for which behaviours collaborative, dyadic, and individual planning 'works' (votes for 28 [100\%], 0 against, 0 abstentions).

- Research is needed to investigate the mechanisms involved in collaborative, dyadic planning vs. individual planning - e.g. social support, social control and commitment, depth of processing (votes for 28 [100\%], 0 against, 0 abstentions).

Of the specific proposed moderators, participants of the expert group saw considerable promise in social support as a means to facilitate more effective execution of planning and implementation intention techniques (Burkert, Knoll, Luszczynska, \& Gralla, 2012; Burkert, Scholz, Gralla, Roigas, \& Knoll, 2011; Prestwich \& Kellar, 2014; Prestwich et al., 2005, 2012). This reflects the proliferation of research examining planning interventions that seek the involvement of significant others in the individuals' decision making and, in the case of collaborative implementation intentions, direct coaction on the behaviour with the individual forming the plan. Although promising, the research on the social aspects of plans is in its infancy, and replication of studies employing dyadic and collaborative implementation intentions to promote health behaviour enactment is needed, as are studies that demonstrate the underpinning mechanisms through the systematic identification and testing of specific mediators.

\section{Preconditions}

It is recommended that researchers ...

- ... integrate content-free pre-planning interventions, for example mental contrasting (Oettingen, 2012, 2014) which, by eliciting wishes and obstacles, facilitates the making of if-then plans and heightens their effects on goal attainment (votes for 19 [68\%], 1 against, 8 abstentions)

- ... investigate processes that link or mediate pre-planning interventions and planning interventions (votes for 28 [100\%], 0 against, 0 abstentions).

- ... investigate contexts that favor the effects of pre-planning interventions on planning and its consequences (votes for 28 [100\%], 0 against, 0 abstentions).

- ... undertake research with participants with low incentive and self-efficacy to change behaviour and how they can be prepared for effective goal pursuit and planning (votes for 25 [89\%], 1 against, 2 abstentions). 
The focus on preconditions reflects participants' recognition of the importance of the circumstances in which planning interventions and implementation intentions will be most effective. The discussions led to the conclusion that there has been little research specifying the precise conditions under which planning interventions and implementation intentions/planning and their associated parameters are formed or developed.

The expert group recommendations regarding established preplanning conditions reflect the need for more evidence to augment and support the formation of implementation intentions with means that will lead to optimal execution of plans. Examples of preplanning conditions that may augment the effectiveness of planning include the use of mental contrasting. Mental contrasting is a self-regulation strategy to promote individuals' understanding of what exactly they want to achieve in the future and what obstacle stands in the way. It also helps individuals to identify what cognitive, affective, and behavioural responses are instrumental to overcoming the obstacle, and it enables forming implicit associations between the obstacle and these responses (Kappes, Singmann, \& Oettingen, 2012). Mental contrasting has been shown to augment the effectiveness of implementation intentions (i.e. mental contrasting with implementation intentions, MCII; Adriaanse et al., 2010; Oettingen, 2012; Oettingen \& Schwoerer, 2013; Stadler, Oettingen, \& Gollwitzer, 2009, 2010). Other examples of pre-planning strategies abound and include self-regulatory strategies that 'pave the way' for effective planning. Many will be related to motivational interventions which may interact with planning interventions. Current recommendations reflect the recognition of the importance of motivation and intention formation as prerequisites for planning interventions and how to pave the way for plan development and use in populations with low motivation and self-efficacy, or ambivalent motives, for behavioural change (Chatzisarantis, Hagger, \& Wang, 2010; Hagger et al., 2012; Koestner, Lekes, Powers, \& Chicoine, 2002; Milne, Orbell, \& Sheeran, 2002).

\section{How people use plans}

Researchers and practitioners should ...

- ... assess the fidelity of planning interventions (votes for 27 [96\%], 0 against, 1 abstention).

- ... conduct process evaluations linking plan use with other intervention components or outcomes (votes for 23 [82\%], 0 against, 5 abstentions).

- ... examine whether combining and sequencing of planning with other intervention techniques affects effectiveness of planning interventions (votes for 27 [96\%], 0 against, 1 abstention).

These expert group recommendations reflect the importance of effective evaluation of planning interventions and, particularly, assessing whether the implementation of interventions is executed as specified in the instructions or protocol, known as intervention fidelity. In the context of implementation intentions, which tend to be self-administered through written instructions provided to individuals by the investigator or interventionist, fidelity has typically been evaluated through a content analysis of the scripts that participants write in the course of developing their plans (e.g. Hagger et al., 2012). A systematic coding of the scripts according to whether they contain the key elements is necessary to ascertain if 
individuals have effectively completed the planning exercise as specified. While this has been conducted in many trials evaluating planning interventions, the adoption of gold standard fidelity checks, including using multiple raters to independently assess the content of plan scripts and conducting inter-rater reliability analysis, is by no mean ubiquitous, and current recommendations have outlined the need to conduct fidelity checks in implementation intention research.

Recently, increased attention has been paid to isolating the effects of specific strategies or techniques adopted to change behaviour (Abraham \& Michie, 2008; Bartholomew et al., 2011; Hagger \& Hardcastle, 2014; Michie et al., 2013; Olander et al., 2013). This is a response to the growing recognition that many interventions aimed at promoting health behaviours tend to adopt multiple techniques leading to difficulties in identifying which aspects of the intervention are affecting behaviour change and how the different components interact in changing behaviour (Michie et al., 2013). The expert group recognised the importance of examining how planning may operate in health behaviour change interventions when utilised alongside other behaviour change techniques (e.g. Adriaanse et al., 2010; Andersson \& Moss, 2011; Hankonen et al., 2015; Knäuper, Roseman, Johnson, \& Krantz, 2009; Koestner et al., 2006; Milne, Orbell, \& Sheeran, 2002; Stadler et al., 2009, 2010). The expert group encourages researchers to adopt caution when developing interventions that use planning alongside other techniques and are urged to adopt appropriate factorial designs to evaluate the unique and interactive effects of planning and accompanying techniques.

\section{Discussion}

The Synergy Expert Group brought together leading theorists and researchers actively involved in the investigation and development of planning interventions in health behaviour contexts. The group aimed to develop a set of recommendations that were expected to serve as a starting point and catalyst for future research endeavours in key areas where evidence is needed and enable researchers to coordinate and direct their efforts in addressing issues likely to make important contributions to furthering the development of effective planning interventions. The Group reached consensus on recommendations for priority areas for future research and practice. Consensus was achieved using a nominal group approach to elicit key issues and consensus voting (Delbecq \& van de Ven, 1971; Fink et al., 1984, 1991; Van de Ven \& Delbecq, 1972). Initial individual work and iterative small group discussions with cross-fertilisation of ideas, followed by plenary discussion, resulted in the identification of an initial list of 42 key issues (Appendix B), which was then refined to a shortlist of priority issues on which the expert group voted to ensure adequate consensus.

An important innovation of the current position statement is the development of a formal definition of planning, including a generic definition of planning and a definition of implementation intentions as a specific form of planning. Agreement on a definition of planning provides an important initial reference point for future planning research, given the considerable variation in definitions and operationalisation of planning constructs in the literature (Hagger \& Luszczynska, 2014). It must be noted that the definition issue was one of the most extensively debated during the course of the meeting and proposed definitions were subject to numerous revisions and amendments. The final definition was agreed by consensus among expert group members, but the 
percentage agreement was joint lowest of all issues (68\%). The main reason for that was that many of the meeting participants were keen to see an overarching definition of planning that incorporated multiple components associated with planning. However, no agreement could be made on the wording of an overarching definition. The final proposal on which participants voted was a generic definition of planning accompanied by a specific definition for implementation intentions. The definition presented represents a general consensus of participating members of the expert group and the disagreements and abstentions reflected some participants' desire for a more detailed all-encompassing definition rather than disagreement with the proposed definition per se. It is important to note that the disagreements and problems surrounding definitions of planning may also be a reflection of different theoretical and epistemological standpoints that exist in the field (e.g. Gollwitzer, 1999; Schwarzer \& Luszczynska, 2008). There has been no previous position statement on a definition of planning, and the current definition should be viewed as neither final nor definitive, but instead an initial step that may help inform further debate on the definition of planning.

We also propose a number of recommendations for future research and practice based on the outcomes of the discussion and voting procedure during the course of the expert meeting. The recommendations are the first attempt to identify research priorities based on the current opinion of an expert group with extensive experience of research and the current literature on implementation intentions and planning in health behavioural contexts. These recommendations received very high $(\geq 79 \%)$ endorsement of the group, substantially higher than the minimum threshold of two-thirds and represents strong agreement among group members. Each recommendation reflects extensions and advances based on their knowledge of current work being conducted by members of the group and others and, as such, areas considered important avenues that will move research and practice in the field forward. Specifically, we propose the following recommendations to guide future researchers' and practitioners' efforts: better testing of mechanisms (eliciting self-regulatory problems; how best to reinforce cue-response strength; best practice in specifying if-then components), guidance on testing the effects of moderators of planning interventions (identifying intrapersonal factors as moderators; identifying the effect of language and mode of delivery; type of response), recommendations on the social aspects of planning (use of collaborative and dyadic planning; conditions and populations for which collaborative and dyadic planning are most effective; mechanisms underpinning collaborative and dyadic planning), necessary considerations of the preconditions that may moderate the effectiveness of planning (investigate the mediators of pre-planning; contextual factors that favour pre-planning; developing implementation intentions for individuals with low incentives and low self-efficacy to change), and recommendations on investigating how people use plans (fidelity of planning interventions; conducting process evaluations linking plans with other intervention techniques; examining combinations and sequences of planning interventions with other intervention techniques).

The only recommendation that did not receive high endorsement was the proposal that researchers should integrate content-free pre-planning interventions to turn individuals into 'expert' planners. The lower level of agreement $(68 \%)$ highlights the issue as one which is potentially controversial or where views were somewhat divergent. Much of the debate on this issue was focused on whether pre-planning interventions should be 'content' free or whether the content should be guided or prompted by 
the researcher or practitioner facilitating the pre-planning intervention. The general view was that eliciting individuals' personal rationales and obstacles in pre-planning interventions may be more effective as they provide person-centred reasons for developing future plans rather than externally referenced reasons which may receive lower endorsement by the individual (Adriaanse et al., 2009; Verhoeven et al., 2014). However, as planning interventions tend to be as effective when imposed by the researcher or practitioner (Armitage, 2009) and individuals may not have the ability to identify appropriate cues, barriers or obstacles, some felt that researcher- or practitioner-driven pre-planning interventions would be at least as, if not more, effective in developing planning expertise. Without research directly testing these effects, these opposing views are speculative and based on the Expert Group's current opinion derived from existing data, and further research that examines pre-planning conditions that compare effectiveness of planning using researcher or practitioner versus personal rationales and obstacles is encouraged.

Overall, the current position statement and recommendations are the result of rigorous discussions of research on planning interventions conducted over the last three decades, including studies conducted by members of the Expert Group (e.g. Adriaanse et al., 2011; Bélanger-Gravel et al., 2013; Carraro \& Gaudreau, 2013; Cook, Gaitán, \& Chater, 2010; Gollwitzer, 2014; Gollwitzer \& Sheeran, 2006; Hagger \& Luszczynska, 2014; Kwasnicka et al., 2013; Oettingen, 2012, 2014; Schwarzer, 2008a). The recommendations are aimed at providing guidance to researchers currently conducting research and developing interventions using planning techniques in health contexts. We anticipate that these recommendations will assist in moving the field forward more rapidly by directing research efforts towards areas where evidence is deficient and needed. We encourage researchers to conduct research in the priority areas identified in the current statement. We anticipate that such research endeavours will contribute to knowledge and understanding of the effects of planning interventions in health contexts, and the underpinning theory and mechanisms involved.

Finally, we would acknowledge that the current statement and recommendations, while based on rigorous debate and emanating from a group of scholars with considerable experience in research on implementation intentions and planning interventions, including those who are at the forefront of the inception and development of the underpinning theory and constructs, should not be regarded as definitive or axiomatic. The views expressed in the position statement reflect those of the expert group based on their collective knowledge, discussion, and analysis of current data and may be revised and modified as new evidence comes to light. Furthermore, the intention of the group is to guide and suggest key issues for future research endeavour rather than confine and narrow research to a limited set of topics. We acknowledge the diversity of research on implementation intentions and planning and acknowledge other important priorities for research exist. We also acknowledge that while the current recommendations focus on implementation intentions as the prototypical form of planning interventions and are confined to this particular type of planning, other conceptualisations of planning in health contexts are prevalent in the scientific literature, with conceptual bases that deviate from those of implementation intentions (Payaprom, Bennett, Alabaster, \& Tantipong, 2011; Taylor, Pham, Rivkin, \& Armor, 1998). We look to future meetings to bring proponents of different perspectives on planning together to debate differences and discuss points of agreement and commonality. 


\section{Strengths and limitations}

The current position statement had a number of strengths. Of pivotal importance was extensive experience and breadth of coverage of participants in the expert group. The review process of applicants took multiple sources of evidence of research and practice in planning interventions into account which meant that the group had considerable expertise in theoretical and conceptual issues, trial design, data management and analysis, and applied practice and translational activities to practitioners and broader audiences. Although the group comprised a number of doctoral students and early-career researchers, many were at the forefront of developing innovative designs and interventions as demonstrated by their publication records reviewed a priori by the Synergy Committee and lead facilitators. In addition, the nominal groups method adopted was effective in developing and exchanging ideas within the group context and also provided a clear method to demonstrate the level of consensus among participants. In addition, the content of the position statement was vetted and approved by all authors in advance, providing further evidence of consent.

We also acknowledge a number of limitations of the current nominal groups approach. The adoption of RAM as an alternative approach may have allowed for the development of more specific practice recommendations based on strong evidence for effectiveness, analyses of potential harms, and chosen objective outcomes. However, that the nominal group approach was considered a good fit for the expert group discussion based on the state of the existing evidence. The approach has advantages in promoting the generation and exchange of ideas and demonstrating consensus among group members on broad issues with respect to planning. The decision to select this approach over other methods (such as the RAM) was based on the facilitators' evaluation of the quality of existing evidence and extent of disagreement in the existing literature in terms of definitions, mechanisms, and outcomes. The nominal group approach, as well as other consensus approaches such as the RAM, may be criticised on the grounds that the results obtained may vary depending on the composition of the panel. Evidence-based recommendations suggest that experts should be sufficiently representative of the disciplines relevant to the subject matter under discussion. However, the current group was considered to have sufficient diversity to warrant adoption of these methods (see Appendix A).

We also acknowledge that the current position statement and discussions of the expert group represent the views and opinions of the group. While there is an acknowledgement that expert groups, provided their membership sufficiently covers the subject areas and has sufficient externally verified levels of expertise, are effective in developing consensus among group members and identifying pressing priorities for future research, the current statement should be acknowledged as one that reflects opinion. The current statement should, therefore, neither be viewed as definitive nor comprehensive. Instead, it should be viewed as a starting point and catalyst for future investigation in a field experiencing rapid expansion and intensity of research as investigators seek to discover the potential and diversity, limits and boundary conditions, of implementation intention and planning interventions. The expert group has highlighted some prominent areas in need of research, but we also stress our recommendations are but one source of information for potential recommendations for future research directions. Our intention was not to limit the diversity of research in the field of implementation intentions nor 
confine researchers to a narrow set of topics. We recognise that other research priorities exist and encourage researchers to pursue high-quality, methodologically rigorous research on implementation intention and planning interventions that advance current thinking and knowledge.

There may have been a number of priority areas that were not discussed or identified during the course of the discussions. For example, a priority area that was not discussed by the expert group but implied by its findings is the need for a rigorous systematic review of implementation intentions and planning interventions in health contexts adopting universally-approved guidelines and methods for search, inclusion, quality and synthesis (e.g. Cochrane Collaboration, Centre for Reviews and Dissemination, PRISMA). While there are reviews and syntheses that have adopted strong methods and criteria, they have tended to be confined to particular health behaviours such as physical activity (Bélanger-Gravel et al., 2013) and healthy eating (Adriaanse et al., 2011). The expanding literature on implementation intention and planning interventions in health behaviour makes such a review timely and would permit subgroup analyses that would enable the issues identified in the current article to be addressed empirically rather than through consensus among experts. In addition, we also acknowledge the need for researchers examining effects of planning interventions to adhere to 'open science' principles (Open Science Collaboration, 2015) such as the need for pre-registration of trials using planning techniques and the submission of data for secondary analyses to allay the potential for publication bias (Pashler \& Harris, 2012) and dubious practices that limit scientific progress and contribution such as ' $p$-hacking' (Head, Holman, Lanfear, Kahn, \& Jennions, 2015), 'salami slicing' (Editorial, 2005), and HARKing (Probst \& Hagger, 2015). Finally, we acknowledge the need for better translational research in planning interventions. Researchers should seek to effectively engage the target audience of their interventions at the planning and development, implementation and evaluation stages (Carr et al., 2011). The acceptability and sustainability of interventions in public health and clinical contexts is paramount if effective techniques developed by health psychologists are to be rolled out on a large scale and be embraced by the practitioners that will be responsible for delivering them to users (Moss-Morris \& Yardley, 2008). ${ }^{5}$

\section{Disclosure statement}

No potential conflict of interest was reported by the authors.

\section{Funding}

Aleksandra Luszczynska's contribution was supported by [Grant number 2014/15/B/HS6/00923] from the National Science Centre, Poland. Sofia López-Roig's participation was supported by a grant from the Spanish Ministry of Economy and Competitiveness [grant number PSI 2011-25132].

Martin Hagger's contribution was supported by a Finland Distinguished Professor Programme (FiDiPro) award from the Academy of Finland and Tekes, the Finnish Funding Agency for Innovation.

\section{Supplemental data}

Supplemental data for this article can be accessed here: http://dx.doi.org/10.1080/08870446.2016. 1146719 


\section{Notes}

1. The five general areas were introduced to the expert group at the outset of the meeting to guide discussions. The goal was not to impose a reified list or preclude discussion of issues that extended beyond these areas. Rather, it was to provide a starting point for group discussions based on a previous review of the literature.

2. It is important to note that the list of priorities are listed in this section and in Appendix C are in the order in which they were put to vote in the expert group meeting and not in order of priority. While there was some variation in the percentage agreement for each priority area, using these percentages as a basis for a hierarchy of priorities would be erroneous. As we have no formal basis for prioritising within the current list, we offer no hierarchy or order within the six areas and 18 issues listed here.

3. Collaborative implementation intentions are defined as developing an if-then plan to enact the target behaviour together with a significant other.

4. Dyadic planning is defined as planning together with significant other, but enacting the behaviour alone without using the partner as a cue.

5. We thank an anonymous reviewer for suggesting these additional priorities.

\section{ORCID}

Martin S. Hagger (D) http://orcid.org/0000-0002-2685-1546

John de Wit (ID http://orcid.org/0000-0002-5895-7935

\section{References}

Abraham, C., \& Michie, S. (2008). A taxonomy of behavior change techniques used in interventions. Health Psychology, 27, 379-387. doi:10.1037/0279-6133.27.3.379

Abraham, C., Sheeran, P., \& Johnston, M. (1998). From health beliefs to self-regulation: Theoretical advances in the psychology of action control. Psychology \& Health, 13, 569-591. doi: $10.1080 / 08870449808407420$

Adriaanse, M. A., de Ridder, D. T. D., \& de Wit, J. B. F. (2009). Finding the critical cue: Implementation intentions to change one's diet work best when tailored to personally relevant reasons for unhealthy eating. Personality and Social Psychological Bulletin, 35, 60-71. doi:10.1177/0146167208325612

Adriaanse, M. A., Oettingen, G., Gollwitzer, P. M., Hennes, E. P., de Ridder, D. T. D., \& de Wit, J. B. F. (2010). When planning is not enough: Fighting unhealthy snacking habits by mental contrasting with implementation intentions (MCII). European Journal of Social Psychology, 40, 1277-1293. doi:10.1002/ejsp.730

Adriaanse, M. A., Vinkers, C. D. W., De Ridder, D. T. D., Hox, J. J., \& De Wit, J. B. F. (2011). Do implementation intentions help to eat a healthy diet? A systematic review and meta-analysis of the empirical evidence. Appetite, 56, 183-193. doi:10.1016/j.appet.2010.10.012

Andersson, E. K., \& Moss, T. P. (2011). Imagery and implementation intention: A randomised controlled trial of interventions to increase exercise behaviour in the general population. Psychology of Sport and Exercise, 12, 63-70. doi:10.1016/j.psychsport.2010.07.004

Armitage, C. J. (2009). Effectiveness of experimenter-provided and self-generated implementation intentions to reduce alcohol consumption in a sample of the general population: A randomized exploratory trial. Health Psychology, 28, 545-553. doi:10.1037/a0015984

Armitage, C. J., \& Conner, M. (2000). Social cognition models and health behaviour: A structured review. Psychology and Health, 15, 173-189. doi:10.1080/08870440008400299

Bartholomew, L. K., Parcel, G. S., Kok, G., Gottlieb, N. H., \& Fernández, M. E. (2011). Planning health promotion programs: An intervention mapping approach (3rd ed.). San Francisco, CA: Jossey-Bass. 
Bélanger-Gravel, A., Godin, G., \& Amireault, S. (2013). A meta-analytic review of the effect of implementation intentions on physical activity. Health Psychology Review, 7, 23-54. doi:10.1080/17437199.2011.560095

Brandstätter, V., Heimbeck, D., Malzacher, J., \& Frese, M. (2003). Goals need implementation intentions: The model of action phases tested in the applied setting of continuing education. European Journal of Work and Organizational Psychology, 12, 37-59. doi:10.1080/ 13594320344000011

Brandstätter, V., Lengfelder, A., \& Gollwitzer, P. M. (2001). Implementation intentions and efficient action initiation. Journal of Personality and Social Psychology, 81, 946-960. doi:10.1037//0022-3514.81.5.946

Burkert, S., Knoll, N., Luszczynska, A., \& Gralla, O. (2012). The interplay of dyadic and individual planning of pelvic-floor exercise in prostate-cancer patients following radical prostatectomy. Journal of Behavioral Medicine, 35, 305-317. doi:10.1007/s10865-012-9416-2

Burkert, S., Scholz, U., Gralla, O., Roigas, J., \& Knoll, N. (2011). Dyadic planning of health-behavior change after prostatectomy: A randomized-controlled planning intervention. Social Science and Medicine, 73, 783-792. doi:10.1016/j.socscimed.2011.06.016

Carr, S. M., Lhussier, M., Forster, N., Geddes, L., Deane, K., Pennington, M., \& Hildreth, A. (2011). An evidence synthesis of qualitative and quantitative research on component intervention techniques, effectiveness, cost-effectiveness, equity and acceptability of different versions of health-related lifestyle advisor role in improving health. Health Technology Assessment, 15, 9. doi:10.3310/hta15090

Carraro, N., \& Gaudreau, P. (2013). Spontaneous and experimentally induced action planning and coping planning for physical activity: A meta-analysis. Psychology of Sport and Exercise, 14, 228-248. doi:10.1016/j.psychsport.2012.10.004

Chapman, J., Armitage, C. J., \& Norman, P. (2009). Comparing implementation intention interventions in relation to young adults' intake of fruit and vegetables. Psychology and Health, 24, 317-332. doi:10.1080/08870440701864538

Chatzisarantis, N. L. D., \& Hagger, M. S. (2010). Effects of implementation intentions linking suppression of alcohol consumption to socialising goals on alcohol-related decisions. Journal of Applied Social Psychology, 40, 1618-1634. doi:10.1111/j.1559-1816.2010.00632.x

Chatzisarantis, N. L. D., Hagger, M. S., \& Wang, C. K. J. (2010). Evaluating the effects of implementation intention and self-concordance on behaviour. British Journal of Psychology, 101, 705-718. doi:10.1348/000712609X481796

Churchill, S., \& Jessop, D. (2010). Spontaneous implementation intentions and impulsivity: Can impulsivity moderate the effectiveness of planning strategies? British Journal of Health Psychology, 15, 529-541. doi:10.1348/135910709x475423

Cook, E., Gaitán, A., \& Chater, A. (2010). From unhelpful to helpful: The role of implementation-intentions in a weight-loss intervention. Health Psychology Update, 19, 11-17. Retrieved from http://shop.bps.org.uk/publications/publication-by-series/health-psychology-update/healthpsychology-update-vol-19-no-1-2010.html

de Bruin, M., Crutzen, R., \& Peters, G.-J. Y. (2015). Everything should be as simple as possible, but this will still be complex: A reply to various commentaries on IPEBA. Health Psychology Review, 9, 38-41. doi:10.1080/17437199.2014.981833

De Vet, E., Oenema, A., Sheeran, P., \& Brug, J. (2009). Should implementation intentions interventions be implemented in obesity prevention: The impact of if-then plans on daily physical activity in Dutch adults. International Journal of Behavioral Nutrition and Physical Activity, 6, 11. doi:10.1186/1479-5868-6-11

de Vries, H., Mesters, I., van de Steeg, H., \& Honing, C. (2005). The general public's information needs and perceptions regarding hereditary cancer: An application of the Integrated Change Model. Patient Education and Counseling, 56, 154-165. doi:10.1016/j.pec.2004.01.002 
Delbecq, A. L., \& van de Ven, A. H. (1971). A group process model for problem identification and program planning. The Journal of Applied Behavioral Science, 7, 466-492. doi:10.1177/ 002188637100700404

Editorial. (2005). The cost of salami slicing. Nature Materials, 4, 1. doi:10.1038/nmat1305

Fink, A., Kosecoff, J., Chassin, M., \& Brook, R. H. (1984). Consensus methods: Characteristics and gudelines for use. American Journal of Public Health, 74, 979-983. doi:10.2105/ AJPH.74.9.979

Fink, A., Kosecoff, J., Chassin, M., \& Brook, R. H. (1991). Consensus methods: Characteristics and guidelines for use. Santa Monica, CA: RAND.

Fitch, K., Bernstein, S. J., Aguilar, M. J., Burnand, B., LaCalle, J. R., Lazaro, P., \& Kahan, J. P. (2001). The RAND/UCLA appropriateness method user's manual. Santa Monica, CA: RAND Corporation.

Fuchs, R., Seelig, H., Göhner, W., Burton, N. W., \& Brown, W. J. (2012). Cognitive mediation of intervention effects on physical exercise: Causal models for the adoption and maintenance stage. Psychology \& Health, 27, 1480-1499. doi:10.1080/08870446.2012.695020

Gollwitzer, P. M. (1990). Action phases and mind-sets. In E. T. Higgins \& R. M. Sorrentino (Eds.), Handbook of motivation and cognition: Foundations of social behavior (Vol. 2, pp. 53-92). New York, NY: Guildford Press.

Gollwitzer, P. M. (1993). Goal achievement: The role of intentions. European Review of Social Psychology, 4, 141-185. doi:10.1080/14792779343000059

Gollwitzer, P. M. (1999). Implementation intentions: Strong effects of simple plans. American Psychologist, 54, 493-503. doi:10.1037/0003-066X.54.7.493

Gollwitzer, P. M. (2014). Weakness of the will: Is a quick fix possible? Motivation and Emotion, 38, 305-322. doi:10.1007/s11031-014-9416-3

Gollwitzer, P. M., \& Brandstätter, V. (1997). Implementation intentions and effective goal pursuit. Journal of Personality and Social Psychology, 73, 186-199. doi:10.1037/0022-3514.73.1.186

Gollwitzer, P. M., \& Sheeran, P. (2006). Implementation intentions and goal achievement: A meta-analysis of effects and processes. Advances in Experimental Social Psychology, 38, 69119. doi:10.1013/S0065-2601(06)38002-1

Gollwitzer, P. M., Sheeran, P., Michalski, V., \& Seifert, A. E. (2009). When intentions go public: Does social reality widen the intention-behavior gap? Psychological Science, 20, 612-618. doi:10.1111/j.1467-9280.2009.02336.x

Hagger, M. S. (2010). Self-regulation: An important construct in health psychology research and practice. Health Psychology Review, 4, 57-65. doi:10.1080/17437199.2010.503594

Hagger, M. S., \& Chatzisarantis, N. L. D. (2014). An integrated behavior change model for physical activity. Exercise and Sport Sciences Reviews, 42, 62-69. doi:10.1249/JES.00000000 00000008

Hagger, M. S., \& Hardcastle, S. J. (2014). Interpersonal style should be included in taxonomies of behaviour change techniques. Frontiers in Psychology, 5, 254. doi:10.3389/fpsyg.2014.00254

Hagger, M. S., Lonsdale, A., Koka, A., Hein, V., Pasi, H., Lintunen, T., \& Chatzisarantis, N. L. D. (2012). An intervention to reduce alcohol consumption in undergraduate students using implementation intentions and mental simulations: A cross-national study. International Journal of Behavioral Medicine, 19, 82-96. doi:10.1007/s12529-011-9163-8

Hagger, M. S., \& Luszczynska, A. (2014). Implementation intention and action planning interventions in health contexts: State of the research and proposals for the way forward. Applied Psychology: Health and Well-Being, 6, 1-47. doi:10.1111/aphw.12017

Hankonen, N., Sutton, S., Prevost, A. T., Simmons, R. K., Griffin, S., Kinmonth, A. L., \& Hardeman, W. (2015). Which behavior change techniques are associated with changes in physical activity, diet and body mass index in people with recently diagnosed diabetes? Annals of Behavioral Medicine, 49, 7-17. doi:10.1007/s12160-014-9624-9 
Head, M. L., Holman, L., Lanfear, R., Kahn, A. T., \& Jennions, M. D. (2015). The extent and consequences of p-hacking in science. PLoS Biology, 13, e1002106. doi:10.1371/journal.pbio. 1002106

Heckhausen, H., \& Gollwitzer, P. M. (1987). Thought contents and cognitive functioning in motivational and volitional states of mind. Motivation and Emotion, 11, 101-120. doi:10.1007/ BF00992338

Jackson, C., Lawton, R., Knapp, P., Raynor, D. K., Conner, M., Lowe, C., \& Closs, S. J. (2005). Beyond intention: Do specific plans increase health behaviours in patients in primary care? A study of fruit and vegetable consumption. Social Science \& Medicine, 60, 2383-2391. doi:10.1016/j.socscimed.2004.10.014

Kanouse, D. E., Winkler, J. D., Kosecoff, J., Berry, S. H., Carter, G. M., Kahan, J. P., ... Brook, R. H. (1989). Changing medical practice through technology assessment: An evaluation of the NIH Consensus Development Program. Ann Arbor, MI: Health Administration Press.

Kappes, A., Singmann, H., \& Oettingen, G. (2012). Mental contrasting instigates goal-pursuit by linking obstacles of reality with instrumental behavior. Journal of Experimental Social Psychology, 48, 811-818. doi:10.1016/j.jesp.2012.02.002

Knäuper, B., Roseman, M., Johnson, P. J., \& Krantz, L. H. (2009). Using mental imagery to enhance the effectiveness of implementation intentions. Current Psychology, 28, 181-186. doi:10.1007/s12144-009-9055-0

Koestner, R., Horberg, E. J., Gaudreau, P., Powers, T., Di Dio, P., Bryan, C., ... Jochum, R. (2006). Bolstering implementation plans for the long haul: The benefits of simultaneously boosting self-concordance or self-efficacy. Personality and Social Psychology Bulletin, 32, 1547-1558. doi:10.1177/0146167206291782

Koestner, R., Lekes, N., Powers, T. A., \& Chicoine, E. (2002). Attaining personal goals: Selfconcordance plus implementation intentions equals success. Journal of Personality and Social Psychology, 83, 231-244. doi:10.1037/0022-3514.83.1.231

Kwasnicka, D., Presseau, J., White, M., \& Sniehotta, F. F. (2013). Does planning how to cope with anticipated barriers facilitate health-related behaviour change? A systematic review. Health Psychology Review, 7, 129-145. doi:10.1080/17437199.2013.766832

Leventhal, H., Diefenbach, M. A., \& Leventhal, E. A. (1992). Illness cognition: Using common sense to understand treatment adherence and affect cognition interactions. Cognitive Therapy and Research, 16, 143-163. doi:10.1007/BF01173486

Lo, S. H., Good, A., Sheeran, P., Baio, G., Rainbow, S., Vart, G., \& von Wagner, C. (2013). Preformulated implementation intentions to promote colorectal cancer screening: A clusterrandomized trial. Health Psychology Review, 33, 998-1002. doi:10.1037/a0033507

Luszczynska, A., Schwarzer, R., Lippke, S., \& Mazurkiewicz, M. (2011). Self-efficacy as a moderator of the planning-behaviour relationship in interventions designed to promote physical activity. Psychology \& Health, 26, 151-166. doi:10.1080/08870446.2011.531571

Luszczynska, A., Sobczyk, A., \& Abraham, C. (2007). Planning to lose weight: Randomized controlled trial of an implementation intention prompt to enhance weight reduction among overweight and obese women. Health Psychology, 26, 507-512. doi:10.1037/0278-6133.26.4.507

Michie, S., Dormandy, E., \& Marteau, T. M. (2004). Increasing screening uptake amongst those intending to be screened: the use of action plans. Patient Education and Counseling, 55, 218-222. doi:10.1016/j.pec.2003.09.005

Michie, S., Richardson, M., Johnston, M., Abraham, C., Francis, J., Hardeman, W., \& Eccles, Martin P. (2013). The behavior change technique taxonomy (v1) of 93 hierarchically clustered techniques: Building an international consensus for the reporting of behavior change interventions. Annals of Behavioral Medicine, 46, 81-95. doi:10.1007/s12160-013-9486-6

Milne, S. E., Orbell, S., \& Sheeran, P. (2002). Combining motivational and volitional interventions to promote exercise participation: Protection motivation theory and implementation intentions. British Journal of Health Psychology, 7, 163-184. doi:10.1348/135910702169420 
Moss-Morris, R., \& Yardley, L. (2008). Current issues and new directions in Psychology and Health: Contributions to translational research. Psychology and Health, 23, 1-4. doi:10.1080/ 08870440802328300

Oettingen, G. (2012). Future thought and behaviour change. European Review of Social Psychology, 23, 1-63. doi:10.1080/10463283.2011.643698

Oettingen, G. (2014). Rethinking positive thinking: Inside the new science of motivation. New York, NY: Penguin.

Oettingen, G., Pak, H. J., \& Schnetter, K. (2001). Self-regulation of goal-setting: Turning free fantasies about the future into binding goals. Journal of Personality and Social Psychology, 80, 736-753. doi:10.1037/0022-3514.80.5.736

Oettingen, G., \& Schwoerer, B. (2013). Mind wandering via mental contrasting as a tool for behavior change. Frontiers in Psychology, 4, 562. doi:10.3389/fpsyg.2013.00562

Olander, E., Fletcher, H., Williams, S., Atkinson, L., Turner, A., \& French, D. (2013). What are the most effective techniques in changing obese individuals' physical activity self-efficacy and behaviour: A systematic review and meta-analysis. International Journal of Behavioral Nutrition and Physical Activity, 10, 29. doi:10.1186/1479-5868-10-29

Open Science Collaboration. (2015). Estimating the reproducibility of psychological science. Science, 349, doi:10.1126/science.aac4716

Orbell, S., Hodgkins, S., \& Sheeran, P. (1997). Implementation intentions and the theory of planned behavior. Personality and Social Psychology Bulletin, 23, 945-954. doi:10.1177/ 0146167297239004

Orbell, S., \& Sheeran, P. (1998). 'Inclined abstainers': A problem for predicting health related behaviour. British Journal of Social Psychology, 37, 151-165. doi:10.1111/j.20448309.1998.tb01162.x

Orbell, S., \& Sheeran, P. (2000). Motivational and volitional components in action initiation: A field study of the role of implementation intentions. Journal of Applied Social Psychology, 30, 780-797. doi:10.1111/j.1559-1816.2000.tb02823.x

Pashler, H., \& Harris, C. R. (2012). Is the replicability crisis overblown? Three arguments examined. Perspectives on Psychological Science, 7, 531-536. doi:10.1177/1745691612463401

Payaprom, Y., Bennett, P., Alabaster, E., \& Tantipong, H. (2011). Using the health action process approach and implementation intentions to increase flu vaccine uptake in high risk Thai individuals: A controlled before-after trial. Health Psychology, 30, 492-500. doi:10.1037/ a0023580

Peters, G.-J. Y., de Bruin, M., \& Crutzen, R. (2015). Everything should be as simple as possible, but no simpler: Towards a protocol for accumulating evidence regarding the active content of health behaviour change interventions. Health Psychology Review, 9, 1-14. doi:10.1080/ 17437199.2013.848409

Prestwich, A., Conner, M., Lawton, R., Bailey, W., Litman, J., \& Molyneaux, V. (2005). Individual and collaborative implementation intentions and the promotion of breast self-examination. Psychology \& Health, 20, 743-760. doi:10.1080/14768320500183335

Prestwich, A., Conner, M. T., Lawton, R. J., Ward, J. K., Ayres, K., \& McEachan, R. R. C. (2012). Randomized controlled trial of collaborative implementation intentions targeting working adults' physical activity. Health Psychology, 31, 486-495. doi:10.1037/a0027672

Prestwich, A., \& Kellar, I. (2014). How can the impact of implementation intentions as a behaviour change intervention be improved? European Review of Applied Psychology, 64, 35-41. doi:10.1016/j.erap.2010.03.00

Probst, T. M., \& Hagger, M. S. (2015). Advancing the rigour and integrity of our science: The registered reports initiative. Stress and Health, 31, 177-179. doi:10.1002/smi.2645

Rhodes, R. E., \& de Bruijn, G. J. (2013a). How big is the physical activity intention-behaviour gap? A meta-analysis using the action control framework. British Journal of Health Psychology, 18, 296-309. doi:10.1111/bjhp.12032 
Rhodes, R. E., \& de Bruijn, G. J. (2013b). What predicts intention-behavior discordance? A review of the action control framework. Exercise and Sport Sciences Reviews, 41, 201-207. doi:10.1097/JES.0b013e3182a4e6ed

Rhodes, R. E., \& Dickau, L. (2012). Experimental evidence for the intention-behavior relationship in the physical activity domain: A meta-analysis. Health Psychology, 31, 724-727. doi: $10.1037 / \mathrm{a} 0027290$

Rhodes, R. E., Fiala, B., \& Nasuti, G. (2012). Action control of exercise behavior: Evaluation of social cognition, cross-behavioral regulation, and automaticity. Behavioral Medicine, 38, 121-128. doi:10.1080/08964289.2012.695411

Scholz, U., Schüz, B., Ziegelmann, J. R., Lippke, S., \& Schwarzer, R. (2008). Beyond behavioural intentions: Planning mediates between intentions and physical activity. British Journal of Health Psychology, 13, 479-494. doi:10.1348/135910707x216062

Schwarzer, R. (2008a). Modeling health behaviour change: How to predict and modify the adoption and maintenance of health behaviors. Applied Psychology: An International Review, 57, 1-29. doi:10.1111/j.1464-0597.2007.00325.x

Schwarzer, R. (2008b). Models of health behaviour change: Intention as mediator or stage as moderator? Psychology and Health, 23, 259-263. doi:10.1080/08870440801889476

Schwarzer, R., Lippke, S., \& Ziegelmann, J. P. (2008). Health action process approach - A research agenda at the Freie Universitat Berlin to examine and promote health behavior change. Zeitschrift Fur Gesundheitspsychologie, 16, 157-160. doi:10.1026/0943-8149.16.3.157

Schwarzer, R., \& Luszczynska, A. (2008). How to overcome health-compromising behaviors The health action process approach. European Psychologist, 13, 141-151. doi:10.1027/10169040.13.2.141

Sheeran, P. (2002). Intention-behavior relations: A conceptual and empirical review. European Review of Social Psychology, 12, 1-36. doi:10.1080/14792772143000003

Sheeran, P., Webb, T. L., \& Gollwitzer, P. M. (2005). The interplay between goal intentions and implementation intentions. Personality and Social Psychology Bulletin, 31, 87-98. doi: $10.1177 / 0146167204271308$

Sniehotta, F. F., Scholz, U., \& Schwarzer, R. (2005). Bridging the intention-behaviour gap: Planning, self-efficacy, and action control in the adoption and maintenance of physical exercise. Psychology and Health, 20, 143-160. doi:10.1080/08870440512331317670

Sniehotta, F. F., Scholz, U., \& Schwarzer, R. (2006). Action plans and coping plans for physical exercise: A longitudinal intervention study in cardiac-rehabilitation. British Journal of Health Psychology, 11, 23-37. doi:10.1348/135910705X43804

Sniehotta, F. F., Schwarzer, R., Scholz, U., \& Schüz, B. (2005). Action planning and coping planning for long-term lifestyle change: Theory and assessment. European Journal of Social Psychology, 35, 565-576. doi:10.1002/ejsp.258

Stadler, G., Oettingen, G., \& Gollwitzer, P. M. (2009). Physical activity in women effects of a self-regulation intervention. American Journal of Preventive Medicine, 36, 29-34. doi:10.1016/j.amepre.2008.09.021

Stadler, G., Oettingen, G., \& Gollwitzer, P. M. (2010). Intervention effects of information and selfregulation on eating fruits and vegetables over two years. Health Psychology, 29, 274-283. doi: $10.1037 / \mathrm{a} 0018644$

Taylor, S. E., Pham, L. B., Rivkin, I., \& Armor, D. A. (1998). Harnessing the imagination: Mental simulation and self-regulation of behavior. American Psychologist, 53, 429-439. doi:10.1037/0003-066X.53.4.429

Van de Ven, A. H., \& Delbecq, A. L. (1972). The nominal group as a research instrument for exploratory health studies. American Journal of Public Health, 62, 337-342. doi:10.2105/ AJPH.62.3.337 
Verhoeven, A. A. C., Adriaanse, M. A., de Vet, E., Fennis, B. M., \& de Ridder, D. T. D. (2014). Identifying the 'if' for 'if-then' plans: Combining implementation intentions with cue-monitoring targeting unhealthy snacking behaviour. Psychology \& Health, 29, 1476-1492. doi:10.1080/ 08870446.2014.950658

Webb, T. L., Christian, J., \& Armitage, C. J. (2007). Helping students turn up for class: Does personality moderate the effectiveness of an implementation intention intervention? Learning and Individual Differences, 17, 316-327. doi:10.1016/j.lindif.2007.03.001

Webb, T. L., \& Sheeran, P. (2004). Identifying good opportunities to act: Implementation intentions and cue discrimination. European Journal of Social Psychology, 34, 407-419. doi:10.1002/ejsp.205

Webb, T. L., \& Sheeran, P. (2006). Does changing behavioral intentions engender behavior change? A meta-analysis of the experimental evidence. Psychological Bulletin, 132, 249-268. doi:10.1037/0033-2909.132.2.249

Webb, T. L., \& Sheeran, P. (2008). Mechanisms of implementation intention effects: The role of goal intentions, self-efficacy, and accessibility of plan components. British Journal of Social Psychology, 47, 373-395. doi:10.1348/014466607X267010

Webb, T. L., Sheeran, P., \& Luszczynska, A. (2009). Planning to break unwanted habits: Habit strength moderates implementation intention effects on behaviour change. British Journal of Social Psychology, 48, 507-523. doi:10.1348/014466608x370591

Webb, T. L., Sniehotta, F. F., \& Michie, S. (2010). Using theories of behaviour change to inform interventions for addictive behaviours. Addiction, 105, 1879-1892. doi:10.1111/j.13600443.2010.03028.x

Weinstein, N. D. (2007). Misleading tests of health behavior theories. Annals of Behavioral Medicine, 33, 1-10. doi:10.1207/s15324796abm3301_1

Wiedemann, A. U., Lippke, S., \& Schwarzer, R. (2012). Multiple plans and memory performance: Results of a randomized controlled trial targeting fruit and vegetable intake. Journal of Behavioral Medicine, 35, 387-392. doi:10.1007/s10865-011-9364-2 